Revista do SELL

v. 5 , no. 1

ISSN: $1983-3873$

\title{
AS VOGAIS POSTÔNICAS NÃO FINAIS NO FALAR DE UBERLÂNDIA, MINAS GERAIS
}

NON-FINAL POSTTONIC VOWELS SPOKEN IN UBERLÂNDIA, MINAS GERAIS

Fabiane Lemes

Universidade Federal de Uberlândia

\begin{abstract}
RESUMO: Esta pesquisa teve como objetivo investigar a ocorrência do alçamento nas vogais médias postônicas não finais no município de Uberlândia, Minas Gerais. Em consequência da posição silábica aqui investigada foram analisadas apenas palavras proparoxítonas. O fenômeno abordado neste trabalho, denominado como alçamento, é caracterizado pela substituição de uma vogal por outra na produção oral, no caso as vogais médias altas /e/ e /o/para as vogais altas /i/ e /u/, como pode ocorrer em bró[co]lis > bró[cu]lis e em hós[pe]de > hós[pi]de. Essa ocorrência foi observada a partir do comportamento de dois processos fonológicos, Redução Vocálica e Harmonia Vocálica, que podem interferir de modo regular na ocorrência ou não do alçamento. Os resultados obtidos demonstram esta relação, além da frequência com que ocorrem e predomínio entre ambas.
\end{abstract}

PALAVRAS-CHAVE: Alçamento; Palavras proparoxítonas; Vogais postônicas não finais.

ABSTRACT: This research aimed to investigate the occurrence of the vocalic raising in mid vowels in non-final posttonic position in the city of Uberlândia, Minas Gerais. As a result of the investigated syllabic position only antepenultimate stressed words were analyzed. The phenomenon discussed in this work, known as vocalic raising is characterized by the replacement of one vowel by another one in the oral production, where the mid high vowels $/ \mathrm{e} / \mathrm{and} / \mathrm{o} /$ to the high vowels /i/ and /u/, as can occur in bró[co]lis > bró [cu]lis and in hós[pe]de > hós[pi]de. This occurrence was observed from the behavior of two phonological processes, Vowel Reduction and Vowel Harmony, which can interfere on a regular basis in the presence or absence of the raising. The results demonstrate this relationship, besides the frequency with which they occur and the predominance between them.

KEYWORDS: Vocalic raising; Antepenultimate stressed words; Non-final posttonic vowels.

\section{Introdução}

A presente pesquisa tem 0 intuito de descrever o comportamento das vogais postônicas não finais no falar de Uberlândia, Minas Gerais, como, por exemplo, nas palavras córr[e]go > córr[i]go, biól[o]go > biól[u]go, que podem sofrer, como nos exemplos apresentados, um alçamento influenciado ora por fatores linguísticos ora por fatores extralinguísticos, como faixa etária, sexo, escolaridade, região.

O alçamento se caracteriza pela substituição de uma vogal por outra, de /e/ > /i/, e de /o/ > /u/, na pronúncia de uma determinada palavra. Com a pronúncia tônica situada na terceira posição à direita, presente nos vocábulos como óp[e]ra, próp[o]lis e búss[o]la, 


\section{Revista do SELL}

v. 5 , no. 1

ISSN: $1983-3873$

com a ocorrência do alçamento, passariam a ser pronunciados como óp[i]ra, próp[u]lis e búss[u]la.

Dizer que uma vogal é postônica significa o mesmo que dizer que esta vogal está posicionada, em uma palavra, depois da sílaba tônica. Nesta pesquisa, delimitar-nosemos na investigação das vogais postônicas em posição não final, restringindo-nos apenas a palavras proparoxítonas.

A importância de se realizar uma pesquisa sobre a área em questão deve-se ao fato de que o contexto postônico não final mostra aspectos distintos. Conforme Câmara Jr (1970), existem quatro inferências possíveis às vogais postônicas em posição não final, sendo elas /i, e, a, u/. Essa afirmação de Câmara Jr caracteriza para Bisol (2003) uma relação assimétrica não apropriada. Justamente por essa instabilidade, Bisol entende que na posição não final as vogais postônicas ora se apresentam em cinco vogais, /i, e, a, o, u/, ora em três /i, a, u/, características do contexto pretônico e postônico final, respectivamente. Câmara Jr propõe, baseando-se na fala culta carioca, que em contexto postônico não final a série anterior não teria sofrido a redução constatada na série posterior.

Tendo em vista a instabilidade do contexto postônico não final observada em outros dialetos do português brasileiro (doravante PB), neste trabalho, pretende-se comprovar que essa assimetria também acontece na cidade de Uberlândia. Nesta análise, investigamos a substituição de uma vogal pela outra, ou seja, o alçamento, que pode levar a uma redução, já que as vogais médias não seriam muito produzidas. Observamos os fatores preponderantes que levam ao alçamento vocálico e também averiguamos se todas as palavras proparoxítonas investigadas mostram o alçamento da vogal média na posição postônica não final. Também foram averiguados os fatores que levariam a esse fenômeno a partir de outras pesquisas já elaboradas e das entrevistas realizadas, buscando também delimitar a estrutura de palavras que estão sujeitas ao alçamento dentro dos campos de análise já supracitados.

Assim, o objetivo principal deste trabalho está relacionado à investigação e à análise do alçamento vocálico postônico em posição não final, especificamente em palavras proparoxítonas produzidas por falantes na cidade de Uberlândia. 


\section{Revista do SELL}

v. 5 , no. 1

ISSN: $1983-3873$

\section{Referencial teórico}

Nesta seção, serão discutidos alguns aspectos que estão direcionados e intrinsecamente ligados às palavras proparoxítonas, além de hipóteses sobre a realização do objeto aqui estudado, o alçamento, bem como fatores preponderantes para que ele se dê. Para o estudo de tal fenômeno, faz-se necessário conhecer as características do ambiente em que ele ocorre, neste caso as palavras proparoxítonas, já que estamos tratando de vogais postônicas em posição não final. Também cabe neste trabalho a apresentação de alguns teóricos e seu posicionamento sobre o processo de alçamento, a partir de pesquisas já realizadas anteriormente.

\subsection{Análises sobre a regra de atribuição de acento nas palavras proparoxítonas no português brasileiro}

Ribeiro (2007) afirma que, na língua portuguesa, o acento recai no máximo até a terceira sílaba da direita para a esquerda. Nesse caso, essas palavras são definidas como proparoxítonas. Assim, nosso sistema linguístico teria espaço para três itens lexicais que seriam os oxítonos que receberiam acento ou tonicidade na última sílaba ou primeira da direita como no caso de café; paroxítonos, em que essa tonicidade recairia na penúltima sílaba ou segunda da direita para a esquerda como em lápis, e os proparoxítonos como em ópera, não sendo aceita uma quarta posição silábica.

Todavia, se nós analisarmos algumas palavras, como Ribeiro nos afirma, como por exemplo, helicóptero e rítmico, poderemos perceber que no momento da pronúncia das respectivas palavras, faz-se necessário a introdução da vogal alta /i/ após as consoantes mudas $/ \mathrm{p} / \mathrm{e} / \mathrm{t} /$. Assim, os acentos dessas palavras recairiam na quarta sílaba da direita para a esquerda, que Lee (1997), chama em seu trabalho de acento ante-proparoxítono, uma vez que se posiciona antes da sílaba denominada proparoxítona.

Essa necessidade a partir da realização oral de se acrescentar vogais a sílabas compostas por consoantes que não precedem uma vogal, ou seja, encontros consonantais, como supracitado nos exemplos, advêm de um processo identificado como epêntese. Esse fenômeno é caracterizado por meio da necessidade de simplificação de uma produção oral. Para isso, haveria a necessidade do acréscimo de um fonema em 


\section{Revista do SELL}

v. 5 , no. 1

ISSN: $1983-3873$

uma produção silábica, o que resultaria, no caso dos exemplos utilizados por Ribeiro em helicóp/i/tero e ríti/mico.

Nesse caso, teríamos um sistema bem mais complexo de acentuação silábica no Português Brasileiro, pois deixaríamos de apresentar três sílabas passíveis de acento e tonicidade que seriam as oxítonas, paroxítonas e proparoxítonas, para quatro ao acrescentarmos as ante-proparoxítonas.

Cabe ressaltar o porquê de se trazer informações relacionadas ao fenômeno da epêntese, que relacionado à necessidade de simplificação oral, se relaciona com o processo de alçamento, objeto de estudo desse trabalho. A partir do esquema abaixo, extraído de Ribeiro (2007: p. 23), essa relação pode ser melhor entendida:

(1) (a)

té. k[i].ni.ca

he.li.có.p[i].te.ro

rí.t[i].mi.co (b)

mó.[gi].no

né.c[i].tar

rá.p[i].to (c)

ó.pe.ra

pró.po.lis

bú.sso.la

Em (a) notamos um reflexo da língua, o que, de certa forma, evidencia o acento "ante-proparoxítono" a partir da epêntese. Em (b), embora as palavras não sejam proparoxítonas, pela mesma justificativa, palavras paroxítonas se constituem oralmente em proparoxítonas, mas que não nos oferecem relevância, por já apresentarem o alçamento uma vez que as vogais em posição não final já são vogais altas. Em (c), foram explanados exemplos de palavras proparoxítonas, grupo de palavras a que nos delimitaremos na presente pesquisa, já que esse estudo trata de vogais postônicas. Seriam essas palavras exemplos que possibilitariam o alçamento $/ \mathrm{e} / \mathrm{/} / \mathrm{i} / \mathrm{e} / \mathrm{o} / \mathrm{/} / \mathrm{u} /$, justamente por oferecerem elementos ideais à ocorrência desse fenômeno. Se alçadas, as palavras presentes em (c), então, passariam a apresentar uma vogal alta /i, u/ no lugar das vogais médias /e, o/.

A presente pesquisa trata da sílaba intermediária entre a sílaba tônica e a última sílaba átona, portanto, exclui-se dessa análise palavras com acento "ante-proparoxítono", pois se as considerarmos, nesses casos, teríamos palavras, como as exemplificadas em (a), que teriam duas posições postônicas não finais, não sendo alvo desta pesquisa. 


\section{Revista do SELL}

v. 5 , no. 1

ISSN: $1983-3873$

\subsection{Proparoxítonas: ocorrência pouco frequente no dia a dia}

Algumas observações surgiram quanto ao uso de palavras proparoxítonas no falar dos indivíduos residentes em Uberlândia. Foi percebido que os termos proparoxítonos não eram tão recorrentes como se previa. Dessa forma, durante as entrevistas que foram realizadas, acreditava-se ser necessário fazer uma indução de vocábulos proparoxítonos por meio de figuras que se relacionem com palavras pertencentes a esse grupo. A questão é que, mesmo antes de começar a pesquisa, houve a dúvida sobre o porquê das palavras proparoxítonas serem tão pouco recorrentes nos diálogos de falantes da cidade de Uberlândia, o que nos levou a essa descrição, topicalizada neste item.

A partir dessa indagação, encontramos referenciais explicativos que indicam que essa ausência de termos proparoxítonos na linguagem rotineira se deve ao fato de esses itens lexicais não ocuparem uma posição de destaque no Português Brasileiro. O que acontece é que os itens lexicais paroxítonos são os mais recorrentes seguidos dos oxítonos, portanto, das três classes, constatamos que as proparoxítonas constituem o menor grupo.

A pouca frequência dessa classe de palavras pode ser explicada devido a reflexos de fatores históricos, como explica Nunes (1989), que descreve esse fator como uma animosidade que a língua apresenta diante de palavras proparoxítonas. Para Bisol (2003), o motivo pelo qual alguns itens proparoxítonos permanecem na língua se deve ao fato de os mesmos serem termos técnicos que se dispõem a resguardar a integridade de seus segmentos. Ainda segundo Bisol, esses termos seriam de uso homogêneo e específicos a uma determinada comunidade. Justamente por esse motivo esses termos teriam uma maior tendência a se resguardarem.

\subsection{Influências no alçamento segundo perspectiva sincrônica}

Para Câmara Jr. (1970), "todos os fonemas vocálicos, em termos fonéticos, apresentam variação articulatória e auditiva, então. Mas o que essencialmente caracteriza as posições átonas é a redução do número de fonemas." (CÂMARA JR: 1970, p. 43). Ora, se tratamos nesta pesquisa de vogais postônicas, também estamos falando de vogais átonas, tendo suma importância o que nos apresenta Câmara Jr. Segundo o pesquisador, a neutralização, que segundo ele é definida pela perda de distinção entre /o/ e /u/, 


\section{Revista do SELL}

v. 5 , no. 1

ISSN: $1983-3873$

depende do posicionamento átono que a vogal assume. Assim sendo, ao se encontrarem em posição postônica, isto é, depois da sílaba tônica, as vogais apresentam "neutralização entre /o/ e /u/, mas não entre /e/ e /il" (p. 44). Para o autor, haveria uma oposição bem maior em relação a /e/ e /i/, o que dificultaria a redução de, por exemplo, a palavra mamífero para mamíf/i/ro, usada também na obtenção de dados da presente pesquisa.

Após essa explicação, Câmara Jr.(1970: p. 44) nos apresenta três quadros correspondentes às vogais átonas no PB, sendo o segundo aquele que representa as vogais postônicas não finais, que estamos abordando no presente estudo.

1ำ quadro (vogais pretônicas):

altas

/u/

/i/

médias

/0/

le/

baixa la/

$2^{\circ}$ quadro (primeiras vogais postônicas dos proparoxítonos, ou vogais penúltimas átonas): altas lu/ /i/

média le/

baixa lal

3ํquadro (vogais átonas finais, diante ou não de /s/ no mesmo vocábulo):

altas

/u/

/i/

baixa

la/

Silva (1999), afirma que "há grande variação de pronúncia de vogais postônicas mediais no português brasileiro" (SILVA: 1999, p. 87). Segundo a pesquisadora, essa variação se relaciona aos diferentes tipos de fala definidos como formal e informal. Ainda segundo a autora, "a ocorrência das vogais /e, o/ e /E, O/1 em posição postônica medial depende sobretudo da vogal tônica que a precede." (SILVA: 1999, p. 87). Câmara Jr. também refere-se ao estilo de fala formal ou informal.

Há, porém, certa flutuação. Um mesmo vocábulo pode ter a forma com /i/ (ou com /u/) ou a forma com /e/ (ou com /o/), de acordo com o registro

\footnotetext{
${ }^{1}$ Os símbolos /E, $\mathrm{O} /$ correspondem às vogais médias baixas. /E/ é a vogal anterior e /O/ é a vogal posterior.
} 


\title{
Revista do SELL
}

v. 5 , no. 1

ISSN: $1983-3873$

informal ou formal, respectivamente, que adota um mesmo falante. (CÂMARA JR.: 1969, p. 24).

Já para Bisol (2003), a explicação para a neutralização, pode ser atribuída ao aparelho fonador humano e à frequência da produção das vogais /i, e, o, u/.

\begin{abstract}
Basta lembrar o diagrama das vogais cardinais de Daniel Jones, que atribui menos espaço bucal às posteriores. As vogais /o, u/ estão mais próximas uma da outra do que as vogais /e, i/. Segundo Martinet (1964: p.139), dado um sistema com o mesmo número de fonemas na série posterior e anterior, as margens de segurança são mais estreitas na série posterior do que na série anterior, o que pode explicar em parte a diferença de comportamento entre as duas séries (BISOL: 2003, p.278-279).
\end{abstract}

Ainda segundo Bisol (2003), a vogal /o/ está mais suscetível ao processo de neutralização do que a vogal/e/ em razão do contexto em que se encontram.

A vogal /o/ na cercania de uma labial /f, v, p, b, m/, como em abóbora e fósforo, muda para /u/ com frequência, como se a comunhão de um traço, a labialidade, fosse um fator que estivesse favorecendo a regra que, por ser variável, pode ocorrer também em contextos não esperados como em pérola. Uma consoante velar, tida como alta, porque pronunciada com o dorso da língua levantado, poderia favorecer a regra como o faz em prólogo, mas tende a deixar de fazê-lo em fonólogo, em variedades do sul. Tem, pois, todas as características de uma regra variável de alçamento (BISOL: 2003, p. 280).

Além dessa influência exercida pelo contexto que permeia as vogais médias ao alçarem para vogais altas, o alçamento também pode se dar devido à frequência, já que muitas palavras utilizadas na elaboração e obtenção dos dados das entrevistas para a realização desta pesquisa são frequentemente usadas na fala popular.

\section{Metodologia}

Para a obtenção dos dados, foram entrevistados 13 (treze) indivíduos. As entrevistas foram feitas individualmente, através de registro de gravação oral em espaço adequado para que haja uma melhor acomodação do entrevistado e para que ele se sinta seguro quanto à gravação feita. Além disso, para complementação, foi elaborada uma lista em que estão dispostos alguns desenhos de objetos para serem especificamente identificados através de vocábulos proparoxítonos. 


\section{Revista do SELL}

v. 5 , no. 1

ISSN: $1983-3873$

Os informantes foram selecionados conforme as seguintes variáveis: a) sexo; b) faixa etária, 25-35 anos; c) ter nascido e ter sido criado na cidade de origem e não ter se afastado por mais de um ano; d) escolaridade, considerando os ensinos fundamental, médio e superior, podendo os mesmos ser completos ou não.

A pesquisa tem predominantemente caráter qualitativo e não quantitativo. Então, neste primeiro momento, nosso objetivo é verificar a presença do alçamento em palavras proparoxítonas, especificamente na posição postônica não final. Posteriormente, é nossa intenção buscar mais elementos que justifiquem a interferência de fatores sociais, como a escolaridade, por exemplo.

Na presente pesquisa, demos destaque à variável estilo uma vez que usamos dois instrumentos para obtenção dos dados, entrevista e nomeação de figuras.

De acordo com Labov (1972), o estilo de fala pode ser determinado a partir da atenção que se dá à fala. Em um primeiro momento de entrevista, Labov diz que ocorre um estilo "cuidado" identificado pela ciência que o falante possui de ser analisado e dessa forma se mostra preocupado com seu desempenho linguístico. Assim, é necessário buscar uma fala espontânea e casual.

Essa fala "espontânea" acontece nos momentos em que o falante se esquece de que está sendo entrevistado, atentando apenas para os eventos expostos. Neste momento da entrevista é presumível que o falante esteja envolvido emocionalmente.

Em situações bem informais, é possível que o pesquisador consiga a fala "casual" que acontece somente quando o informante se sente relaxado, não se preocupando com sua fala. Ainda segundo Labov, existem saídas para quebrar a formalidade da entrevista, mas que, independente delas, a fala obtida nessa situação apenas se aproxima do estilo usado no dia a dia pelo falante com a família ou com os amigos. A esse estilo do dia a dia, Labov chama de vernáculo.

Segundo o estilo de fala, Viegas afirma:

Parece óbvio, mas é interessante observarmos o que a variação em termos de estilo significa. Se determinada pessoa muda sua linguagem dependendo da situação, ou contexto social, isto quer dizer que as implicações do contexto estão presentes na sua linguagem. Os valores sociais que a pessoa interiorizou são expressos através da sua linguagem. Por tudo isso esta variável -ESTILO- deve ser investigada. (VIEGAS: 1987, p. 70). 


\section{Revista do SELL \\ v. 5 , no. 1 \\ ISSN: $1983-3873$}

A progressão da formalidade da fala é contínua, pois numa ponta há um estilo bem informal, na outra um estilo bem formal. Em se tratando do estilo, a segmentação de uma entrevista é trabalho de grande dificuldade, pois ao se preocupar com o gravador, o entrevistado elabora a fala que julga mais apropriada, faz perguntas a respeito da finalidade da entrevista, entre outros.

Para minimizar os efeitos de formalidade, optou-se por identificar um perfil semelhante dos entrevistados, excetuando-se apenas a variável escolaridade. Também, procuramos obter os dados a partir de dois instrumentos de obtenção de dados, a entrevista e a nomeação de figuras.

Após a gravação das entrevistas, as transcrições fonéticas foram realizadas e os dados analisados criticamente para a identificação do alçamento vocálico objetivado na pesquisa em questão no dialeto dos uberlandenses.

\section{Processos fonológicos: alçamento e harmonia vocálica}

Como já dito anteriormente, o tópico aqui investigado é o fenômeno do alçamento que se caracteriza pela elevação do traço de altura da vogal média alta /e/ para a vogal alta /i/ (de pêss[e]go para pêss[i]go), e da vogal média alta /o/ para a vogal alta /u/ (de bróc[o]lis para bróc[u]lis). Para que possamos entender esse fenômeno é necessário que tenhamos algumas noções importantes que influenciam e contribuem para sua ocorrência.

No que se refere ao alçamento, existem duas propostas de regra, a harmonização vocálica e o enfraquecimento da vogal por assimilação dos traços consonantais adjacentes. Passos, Passos e Araújo (1980), Abaurre-Gnerre (1981), Viegas e Veado (1982) se posicionam contra uma regra categórica e mencionam contextos que exageram a harmonização vocálica.

Passos, Passos e Araújo (1980) estudaram a estrutura da sílaba, demonstrando sua atuação na regra do alçamento. Além deste estudo, a relação entre o alçamento e o enfraquecimento é vastamente anunciada em trabalhos linguísticos. No entanto, o alçamento seria mais frequente no meio ou no fim da palavra do que no início, que é a posição forte da sílaba em palavras proparoxítonas. 


\section{Revista do SELL}

v. 5 , no. 1

ISSN: $1983-3873$

De acordo com Wetzels (1992), nota-se que a diferença entre as vogais altas /i/ e /u/ e as vogais médias altas /e/ e /o/ dá-se por meio do traço [aberto 2], como veremos no quadro abaixo.

\begin{tabular}{|c|c|c|c|c|c|c|}
\hline \multirow{4}{*}{$\begin{array}{l}\text { Quadro } \\
\text { sistema }\end{array}$} & Altura & $\mathrm{i} / \mathrm{u}$ & e /o & $\mathrm{E} / \mathrm{O}$ & a & \multirow{4}{*}{$\begin{array}{l}\text { 1. Distinção de altura no } \\
\text { vocálico, proposto por } \\
\text { (1992). }\end{array}$} \\
\hline & Aberto 1 & - & - & - & + & \\
\hline & Aberto 2 & - & + & + & + & \\
\hline & Aberto 3 & - & - & + & + & \\
\hline
\end{tabular}

Tomando como base essa proposta, notamos que a distinção entre as vogais altas /i/ e /u/ e as vogais médias altas /e/ e /o/ se dá a partir do traço [aberto 2]. Essa teoria possibilita comentar que, quando há a ocorrência do alçamento das vogais /e/ e /o/ postônicas não finais, há o apagamento do traço [aberto 2], acontecendo o que chamamos de neutralização entre as vogais médias altas e as vogais altas.

Um aspecto relevante para que compreendamos essas noções se refere ao quadro vocálico do português brasileiro proposto por Câmara Jr, já que sua abordagem sobre as vogais do PB é a mais completa já realizada. O esquema a seguir se baseia na constatação de que é a partir da posição tônica que os fonemas vocálicos são classificados.

(2) altas

médias

médias

baixas /u/

lô/

/ò/

la/

posteriores central anteriores

A partir desse quadro, podemos apontar alguns processos que possibilitam o envolvimento de vogais em posição postônica não final como o alçamento, ou redução vocálica (doravante RV) e a harmonia vocálica (doravante HV). Ambos os fenômenos ocorrem por um processo fonológico e se diferem entre si. A HV se caracteriza no momento em que a vogal média alta passa a ser alta, dependendo do acordo entre as vogais encontradas no mesmo vocábulo, como em m[i]nino. De acordo com Bisol (1981), 


\section{Revista do SELL}

v. 5 , no. 1

ISSN: $1983-3873$

esse fenômeno tem uma maior preponderância em posição pretônica. Já o alçamento pode ocorrer em todas as vogais com exceção das tônicas.

Crystal (1988) afirma que o processo de harmonia pode ser definido como a maneira que a articulação de uma determinada unidade fonológica é influenciada por outra unidade, na mesma palavra ou sintagma, sendo a HV um dos principais, juntamente com a harmonização consonantal.

Para Silva (1999), a vogal tônica influencia diretamente na qualidade da vogal postônica não final. Assim, uma vogal alta em posição tônica influenciaria uma vogal média alta em posição átona, o que de acordo com essa hipótese tornaria essa vogal média átona /e, o/ em alta /i, u/, como no caso das palavras citadas abaixo usadas na realização da presente pesquisa, mam[íffero, s[i]mbolo, frut[í]fera, n[ú]mero, veloc[í]metro, [ú]tero, b[ú]ssola, v[í]bora, veloc[í]pedes, ind[í]gena, carn[í]voro, paralelep[í]pedo, entre outras. Outros teóricos, como Amaral (2001), defendem que esse processo também pode ocorrer por meio de assimilação. Nesse caso, uma sílaba átona, seja ela pretônica ou postônica, assimila os traços de altura da sílaba tônica, podendo essa assimilação ser progressiva ou regressiva, dependendo da posição em que se encontra a sílaba assimilada.

Assim, a assimilação progressiva seria quando o assimilado é influenciado pelo assimilador, ou seja, o fonema fraco é influenciado pela sílaba tônica. Já a assimilação regressiva, como o próprio nome já diz, se daria quando o assimilado precedesse o assimilador, como no caso de col[éjgio. Essa última definição, portanto, é irrelevante nesta pesquisa, por não ocorrer em palavras proparoxítonas, que são o objeto de estudo desse trabalho.

De acordo com Ribeiro (2007), as variáveis linguísticas e extralinguísticas influenciam no processo de alçamento das vogais /e/ e /o/ postônicas não finais e finais em um estudo variacionista realizado. A autora sugeriu, em seu trabalho, que o alçamento das vogais /e/ e /o/ postônicas não finais é um processo que está sofrendo modificações em desenvolvimento. 


\section{Revista do SELL}

v. 5 , no. 1

ISSN: $1983-3873$

\section{Análise de resultados}

A partir dos aspectos relatados nas seções anteriores, há a percepção de que existem vários motivos que podem influenciar o alçamento das vogais não finais em palavras proparoxítonas.

Apesar da possibilidade de se alcançar resultados significativos sobre o alçamento das vogais postônicas, vale lembrar que grande parte dos trabalhos desenvolvidos sobre esse fenômeno estão destinados à sua análise em posição pretônica, na qual a vogal analisada é aquela que precede a sílaba tônica, nesse caso, a vogal se encontra em posição contrária à postônica, que está localizada posteriormente a esse item lexical.

Dessa forma, objetiva-se mostrar quais são os fones que ocorrem em posição postônica não final e apresentam alçamento na cidade de Uberlândia, município em que essa pesquisa foi realizada. Tomamos por referência a afirmação de Bisol (2003) que defende que a vogal média /o/ tem uma maior facilidade de alçar do que a vogal média /e/, e salienta que quando essas vogais estão cercadas por consoantes labiais ou velares, há uma maior probabilidade da ocorrência do alçamento, em razão da comunhão de traços que as respectivas vogais apresentam com essas consoantes por razões contextuais.

Outro aspecto importante que também pode ser aceito é o que Bisol (2003) apresenta em seu trabalho ao dizer que a frequência relacionada à presença de itens lexicais posteriores /o, $\mathrm{u} / \mathrm{e}$ anteriores /e, i/ está intrinsecamente ligada a essa variação fonológica. A partir de seu trabalho, conclui-se que o alçamento com vogais pertencentes à série posterior é mais frequente do que em vogais de série anterior.

A partir dessas considerações, pretende-se investigar quais contextos fonológicos estão envolvidos no processo de alçamento das vogais postônicas não finais, bem como seu envolvimento na realização desse fenômeno.

É possível considerar que os processos de harmonia vocálica e de redução vocálica interferem na realização do alçamento. É importante destacar que em se tratando de alçamento o que se espera é o processo de RV na ocorrência do fenômeno, porém, associada a esta redução, é possível nomear alguns casos mais regulares de HV.

A RV ocorre quando vogais de articulação longa e significativamente sonoras são reduzidas, tornando-se breves. Outro motivo pelo qual é possível que ocorra a RV, segundo Trask (1996), relaciona-se a qualquer processo fonológico que torna uma vogal 


\section{Revista do SELL}

v. 5 , no. 1

ISSN: $1983-3873$

mais curta, menos sonora, mais baixa conforme sua entonação ou mais central em termos de sua qualidade, ou ainda que neutraliza alguns contrastes vocálicos em posição não acentuada. Assim, a palavra brócolis apresenta alçamento pelo processo de RV, tornando-se bróculis.

Já a HV, que acontece nas vogais postônicas por meio da assimilação, se caracteriza pela influência que uma sílaba exerce sobre a outra. Então, a HV ocorre quando a sílaba, nesse caso a postônica, assimila um ou mais traços da sílaba anterior. Nesse caso, palavras como bússola, que possui uma vogal média /o/ em posição postônica não final, sofreria a influência da vogal alta /u/ presente na sílaba anterior. Assim, a vogal média /o/, em caso de ocorrência do alçamento por HV, se tornaria /u/, o que acarretaria a ocorrência de duas vogais altas, trazendo como resultado a palavra bússula.

Outro fator relevante desta pesquisa é o comportamento dos falantes no momento em que foram entrevistados. Inicialmente, houve uma conversa informal com cada um dos participantes, a fim de descontraí-los e deixar a conversa o mais informal possível. A presença de um gravador e mesmo do documentador poderia inibir o falar mais espontâneo e apresentar uma maior preocupação ou cuidados com a fala, ocasionando certa formalidade.

Dessa forma, os 13 (treze) entrevistados na presente pesquisa estiveram à vontade, o que possibilitou uma coleta de dados de alta qualidade, atingindo assim o objetivo pretendido. E como, além da entrevista, foi considerada a nomeação de figuras, foi possível a obtenção das palavras paroxítonas necessárias para a análise.

Durante a realização das entrevistas, foi proposto um total de 54 (cinquenta e quatro) palavras proparoxítonas. Desse total, 30 (trinta) foram discriminadas também por meio de imagens. Assim, em certo momento da conversa, foi entregue aos participantes uma lista contendo todas essas palavras, além de outra lista na qual se dispunham figuras correspondentes à parte dessas palavras como supracitado.

A escolha das palavras representadas por figuras foi feita a partir da possibilidade de concretude. Entretanto, como algumas palavras são abstratas e impossíveis de serem representadas por meio de imagens, tornou-se impossível a interligação de todas as palavras analisadas às suas respectivas ilustrações.

Após a entrega das duas listas, foi pedido aos entrevistados que fizessem a identificação no momento em que eles encontrassem alguma figura que correspondesse 


\section{Revista do SELL}

v. 5 , no. 1

ISSN: $1983-3873$

a alguma palavra. Ao final da identificação, foi sugerido que os participantes lessem as palavras não identificadas e em seguida foi perguntado se alguma dessas imagens era marcante e, caso a resposta fosse positiva, que explicassem o motivo.

Abaixo estão dispostas todas as palavras usadas na realização da presente pesquisa, além da marcação da ocorrência ou não do alçamento. Como nem todos os falantes pronunciaram todas as palavras, a ocorrência do alçamento deve ser considerada proporcionalmente em relação à realização de cada vocábulo.

\begin{tabular}{|l|c|c|}
\hline \multicolumn{1}{|c|}{ PALAVRAS } & ALÇAMENTO & NÃO ALÇAMENTO \\
\hline Abóbora & 1 & 12 \\
\hline Âncora & 0 & 13 \\
\hline Parábola & 3 & 0 \\
\hline Almôndega & 0 & 12 \\
\hline Símbolo & 8 & 3 \\
\hline Próspero & 0 & 3 \\
\hline Brócolis & 11 & 1 \\
\hline Auréola & 7 & 4 \\
\hline Câmera & 0 & 10 \\
\hline Centímetro & 0 & 12 \\
\hline Árvore & 0 & 13 \\
\hline Pêssego & 0 & 13 \\
\hline Cérebro & 0 & 13 \\
\hline Cócega & 0 & 3 \\
\hline Fôlego & 0 & 4 \\
\hline Fósforo & 5 & 13 \\
\hline Frutífera & 0 & 6 \\
\hline Hipódromo & 0 & 3 \\
\hline Mármore & 0 & 3 \\
\hline Helicóptero & 0 & 13 \\
\hline Número & 0 & 11 \\
\hline Pálpebras & 0 & 3 \\
\hline Parênteses & 1 & 12 \\
\hline Psicólogo & 0 & 4 \\
\hline Quilômetro & 0 & 9 \\
\hline Velocímetro & 0 & 13 \\
\hline Útero & 0 & 13 \\
\hline Termômetro & 0 & 13 \\
\hline Vértebra & 0 & 8 \\
\hline Adúltero & 0 & 2 \\
\hline Autódromo & 0 & 2 \\
\hline Crisântemo & 0 & 3 \\
\hline Fenômeno & 0 & 4 \\
\hline Gôndola & 0 & 4 \\
\hline Bússola & 6 & 12 \\
\hline & & \\
\hline & 0 & 13 \\
\hline
\end{tabular}




\section{Revista do SELL}

v. 5 , no. 1

ISSN: $1983-3873$

\begin{tabular}{|l|c|c|}
\hline Horóscopo & 1 & 3 \\
\hline Hóspede & 2 & 4 \\
\hline Ópera & 0 & 2 \\
\hline Pentágono & 3 & 12 \\
\hline Víbora & 0 & 12 \\
\hline Apóstolo & 1 & 3 \\
\hline Mamífero & 0 & 10 \\
\hline Semáforo & 2 & 13 \\
\hline Velocípedes & 3 & 12 \\
\hline Córrego & 0 & 13 \\
\hline Diálogo & 0 & 3 \\
\hline Indígena & 3 & 12 \\
\hline Autódromo & 0 & 2 \\
\hline Gênese & 0 & 2 \\
\hline Pérola & 5 & 12 \\
\hline Carnívoro & 1 & 6 \\
\hline Cômoda & 1 & 12 \\
\hline Época & 0 & 3 \\
\hline Paralelepípedo & 0 & 3 \\
\hline
\end{tabular}

Quadro 2. Palavras analisadas e ocorrência do alçamento

No quadro 2 foram apresentadas todas as palavras utilizadas nas entrevistas, independentemente se alçaram ou não. A partir da análise deste quadro, constatamos que apenas 18 (dezoito) das 54 (cinquenta e quatro) palavras utilizadas nas entrevistas sofreram o fenômeno do alçamento. Vale lembrar que se todos os falantes tivessem pronunciado todas as palavras, o que não se realizou, mais palavras poderiam ter alçado. Cabe, então, considerar a possibilidade de investigar mais palavras proparoxítonas em pesquisas futuras.

O processo de alçamento pode decorrer a partir de dois fatores que englobam todas as justificativas aqui expressas anteriormente, que se trata da redução vocálica e da harmonia vocálica. Dessa forma, dividiremos as palavras que sofreram alçamento em dois grupos, sendo que a partir dessa divisão uma análise mais aprofundada será feita.

Abaixo, segue outra tabela que considera somente as palavras alçadas pela redução vocálica.

\begin{tabular}{|l|c|}
\hline \multicolumn{1}{|c|}{ Palavras } & $\begin{array}{c}\text { Realização do Alçamento por Redução } \\
\text { Vocálica }\end{array}$ \\
\hline Abóbora & 1 \\
\hline Parábola & 3 \\
\hline Brócolis & 11 \\
\hline
\end{tabular}


Revista do SELL

v. 5 , no. 1

ISSN: $1983-3873$

\begin{tabular}{|l|l|}
\hline Auréola & 7 \\
\hline Fósforo & 5 \\
\hline Parênteses & 1 \\
\hline Horóscopo & 1 \\
\hline Hóspede & 2 \\
\hline Pentágono & 3 \\
\hline Apóstolo & 1 \\
\hline Semáforo & 2 \\
\hline Pérola & 5 \\
\hline Cômoda & 1 \\
\hline
\end{tabular}

Quadro 3. Processo de alçamento por redução vocálica

A partir do quadro 3, averiguamos que das 18 (dezoito) palavras que sofreram interferência pelo processo de alçamento, 13 (treze) apresentaram a influência da RV, ou seja, $73 \%$. Nesse caso, é possível que o falante busque no dia a dia adequar o tempo das sílabas ao tornar a vogal média mais breve, tornando-a assim mais alta, o que a faria parecer menor. Nesse caso, esse processo se daria com o intuito de que essas palavras se tornassem parecidas com as palavras mais usadas em seu cotidiano, no caso as paroxítonas. Neste caso, poderíamos, inclusive, considerar a possibilidade de algumas palavras proparoxítonas apresentarem a supressão da vogal em posição postônica não final, como em semáf[u]ro, que pode ser realizada como semáfro.

Abaixo são consideradas apenas as palavras que alçaram por meio da harmonia vocálica, que seria uma possível explicação para a ocorrência do alçamento, observando que a harmonia que acontece em posição pretônica também poderia ocorrer em posição postônica, por meio de um processo assimilatório.

\begin{tabular}{|l|c|}
\hline \multicolumn{1}{|c|}{ Palavras } & $\begin{array}{c}\text { Realização do Alçamento por Harmonia } \\
\text { Vocálica }\end{array}$ \\
\hline Símbolo & 8 \\
\hline Bússola & 6 \\
\hline Velocípedes & 3 \\
\hline Indígena & 3 \\
\hline Carnívoro & 1 \\
\hline
\end{tabular}

Quadro 4. Processo de alçamento por harmonia vocálica

A partir do quadro acima, verificamos que apenas 5 (cinco) das 18 (dezoito) palavras alçadas sofreram esse processo por meio da harmonia vocálica. Assim, a 


\section{Revista do SELL}

v. 5 , no. 1

ISSN: $1983-3873$

influência da HV no processo de alçamento da presente pesquisa não foi tão relevante pensando-se no direcionamento progressivo, uma vez que um percentual muito pequeno de aproximadamente $27 \%$ de palavras apresentou na sílaba postônica a assimilação do traço de altura da sílaba tônica.

Durante a realização desta pesquisa, e após a análise das entrevistas e dos quadros explícitos até aqui, chegamos ao resultado de que $34 \%$ do total de palavras analisadas sofreram alçamento por meio dos processos de redução vocálica e harmonia vocálica, o que de maneira geral é um percentual baixo, diferentemente do que se esperava no início da pesquisa, em que se acreditava que esse percentual pudesse atingir uma marca um pouco maior.

Mesmo a partir dessa baixa constância de realização do fenômeno aqui estudado, as hipóteses apresentadas anteriormente foram confirmadas.

Constatamos aqui o posicionamento de Bisol (2003), em seu trabalho, quando aponta que o contexto apresenta uma forte influência na ocorrência do alçamento, quando as vogais estão cercadas por consoantes labiais e velares, exatamente como foi constatado na análise dos dados obtidos. Observa-se que as palavras abób[u]ra, paráb[u]la, hósp[i]de, côm[u]da, símb[u]lo e velocíp[i]des apresentam uma consoante labial como contexto antecedente e as palavras bróc[u]lis, horósc[u]po e pentág[u]no apresentam uma consoante velar antecedente. Dessa forma, pode-se afirmar que a articulação de uma determinada unidade fonológica exerce uma influência significativa em outra unidade, o que também chamamos de assimilação.

Também afirmamos o que Bisol (2003) apresenta em sua pesquisa ao dizer que a presença de itens lexicais anteriores e posteriores está diretamente ligada à realização do alçamento, uma vez que essa ocorrência se daria devido ao aparelho fonador humano. Assim, a proximidade das articulações de produção das vogais /o, u/ apresentaria uma maior preponderância ao alçamento da vogal posterior devido à frequência, diferentemente da vogal alta anterior, que apresentaria uma menor incidência de alçamento.

A partir do quadro 2 fica confirmada essa hipótese, pois das 18 (dezoito) palavras que alçaram apenas 4 (quatro) apresentaram a alternância da vogal /e/ para /i/ em posição postônica, que foram os vocábulos parêntesis, hóspede, velocípedes e indígena, que com o alçamento, passaram a ser pronunciadas como parêntises, hóspide, 


\section{Revista do SELL}

v. 5 , no. 1

ISSN: $1983-3873$

velocípides e indígena, confirmando o que Bisol (2003) defende quando diz que a vogal /o/ apresenta uma maior possibilidade de alçar do que a vogal /e/.

Silva (1999) também apresenta uma justificativa plausível para a ocorrência desse fenômeno. Segundo a pesquisadora, as situações de formalidade e informalidade agem diretamente no fenômeno do alçamento. Acredita-se que justamente por este motivo, uma quantidade menor de palavras do que a prevista inicialmente tenha alçado, pois mesmo recorrendo a alguns meios como a conversa e a descontração para que os informantes se sentissem à vontade, a presença do gravador talvez tenha influenciado na pronúncia de algumas palavras, deixando os entrevistados inibidos.

É importante lembrar e salientar a importância de se levantar uma quantidade maior de dados para que seja feita uma pesquisa mais abrangente a respeito da interferência dos fatores linguísticos e sociais na língua, uma vez que apenas com uma quantidade considerável de dados é possível de fato averiguar a influência que os fatores internos e externos à língua podem acarretar nos resultados obtidos de uma pesquisa.

\section{Considerações finais}

No decorrer desta pesquisa investigamos e analisamos a ocorrência do alçamento das vogais médias em posição postônica não final dos itens lexicais proparoxítonos no falar de indivíduos da cidade de Uberlândia, Minas Gerais. Essa investigação foi feita a partir do alçamento, principalmente no que se refere à redução vocálica e à harmonia vocálica.

De acordo com o que foi apresentado por Câmara Jr. (1970), o processo de alçamento ocorreria por meio da neutralização entre as vogais posteriores $/ \mathrm{o}, \mathrm{u} /$, mas não entre as vogais anteriores /e, i/, pois este segundo caso seria pouco aceitável do ponto de vista auditivo. Nos resultados obtidos aqui comprovou-se que a realização do alçamento realmente é mais recorrente em itens lexicais posteriores, porém algumas palavras, como parênt[e]sis, hósp[e]de, velocíp[e]des e indíg[e]na, que apresentam em posição postônica vogais anteriores, mostraram a ocorrência do alçamento: parênt[i]ses, hósp[i]de, velocíp[i]des e indíg[i]na.

Bisol (2003) também defende que o alçamento é mais recorrente em séries de vogais posteriores, justificando essa predominância em razão do efeito causado pela frequência do aparelho fonador humano, uma vez que /o/ e /u/ estão mais próximas 


\section{Revista do SELL}

v. 5 , no. 1

ISSN: $1983-3873$

foneticamente do que /e/ e /i/. Apesar de seu posicionamento, Bisol nos lembra que o alçamento também pode acontecer em séries de vogais anteriores, embora seja menos frequente, o que justifica o alçamento das vogais em posição postônica nas palavras exemplificadas no parágrafo anterior.

Câmara Jr. (2002) também traz uma justificativa bastante plausível no que concerne à realização do fenômeno aqui estudado. Segundo o autor, o alçamento, ou redução quando tratamos de /e/ e /o/ em algumas posições átonas, acontece em consequência da posição átona que a vogal assume. No entanto, as posições átonas que estudamos aqui estão mais sujeitas à neutralização da oposição de $/ \mathrm{o}>\mathrm{u} /$ do que de $/ \mathrm{e}>$ i/. Ainda segundo Câmara Jr, essa oscilação entre /e, o/ e /i, u/, respectivamente, não são influenciadas pelo timbre, mas pela "norma fonológica que oscila entre duas pautas vocálicas" (CÂMARA JR.: 2002, p. 21). Nesse caso, o processo influenciador seria a assimilação, que é mais frequente em vogais que ocupam posição postônica, ao contrário da harmonia vocálica que é mais frequente nas vogais em posição pretônica.

A partir dos dados levantados na presente pesquisa, conclui-se que o processo de maior relevância e, portanto, mais influente na realização do alçamento, é o da redução vocálica, já que uma grande parte das palavras alçadas sofreu esse fenômeno em razão justamente desse processo, que se caracteriza por tornar vogais de articulação longa e significativamente sonoras em breves.

\section{Referências}

ABAURRE-GNERRE, M. B. M. Processos fonológicos segmentais como índices de padrões diversos nos estilos formal e casual do Português do Brasil. Cadernos de estudos linguísticos. Campinas. UNICAMP, № 2, 1981, p.23-43.

BISOL, L. Harmonia vocálica: uma regra variável. Tese (Doutorado). Universidade Federal do Rio de Janeiro. Rio de Janeiro, 1981.

A Neutralização das Átonas. Revista Letras. Curitiba, ํㅡㄴ, especial, Editora UFPR, p. 273-283, 2003.

CÂMARA JR., J. M. Estrutura da língua portuguesa. Petrópolis: Vozes, 1970.

Problemas de Lingüística Descritiva. 19 ed. Petrópolis: Vozes, 2002.

CRYSTAL, D. Dicionário de linguística e fonética. Jorge Zahar Editor Ltda. RJ, 1988 
LABOV, W. (1972) Sociolinguistic Patterns. Philadelphia, University of Pennsylvânia Press.

LEE, S. H. O Acento Primário do Português do Brasil. Revista de Estudos da Linguagem,

Belo Horizonte, p.5-30, 1997.

NUNES, J. J. Compêndio de Gramática Histórica da Língua Portuguesa. Lisboa: Clássica, 1989, p. 55-69.

RIBEIRO, D. F. S. Alçamento de vogais postonicas não finais no português de Belo Horizonte - Minas Gerais: uma abordagem difusionista. Belo Horizonte: EDIPUCMG, 2007

PASSOS, C.; PASSOS, M. E.; ARAÚJO, S. S. Implicações teóricas do levantamento prétônico do Português, in Anais do V Encontro nacional de Linguística. Rio de Janeiro, PUC/RJ. Vol. 1, 1980. P. 233-242.

SILVA, T. C. Fonética e fonologia do português: roteiro de estudos e guia de exercícios. São Paulo: Contexto, 1999.

TRASK, R. L. A dictionary of phonetics and phonology. London: Routledge, 1996.

VIEGAS, M. do C. Alçamento de vogais pretônicas: uma abordagem sociolinguística. UFMG. 1987.

VIEGAS, M. do C.; VEADO, R. M. A. Alçamento de vogais pretônicas. In: VEADO, R.; ALVARENGA, D. (Orgs.). Ensaios de linguística. Belo Horizonte, UFMG, oํ 7, 1982, p. 53-70.

WETZELS, W. L. Mid Vowel Neutralization in Brazilian Portuguese. Caderno de Estudos Lingüísticos, Campinas, n.23, Jul/Dez, 1992, p.19-55. 